\title{
Bioconversion of ferulic acid attained from pineapple peels and pineapple crown leaves into vanillic acid and vanillin by Aspergillus niger I-1472
}

\author{
Pei Ling Tang ${ }^{1 *}$ (i) and Osman Hassan ${ }^{2}$
}

\begin{abstract}
This study was conducted to evaluate the potential of pineapple peel (PP) and pineapple crown leaves (PCL) as the substrate for vanillic acid and vanillin production. About $202 \pm 18 \mathrm{mg} \mathrm{L}^{-1}$ and $120 \pm 11 \mathrm{mg} \mathrm{L}^{-1}$ of ferulic acid was produced from the PP and PCL respectively. By applied response surface methodology, the ferulic acid yield was increased to $1055 \pm 160 \mathrm{mg} \mathrm{L}^{-1}$ by treating $19.3 \%$ of PP for $76 \mathrm{~min}$, and $328 \pm 23 \mathrm{mg} \mathrm{L}^{-1}$ by treating $9.9 \%$ of $\mathrm{PCL}$ for $36 \mathrm{~min}$ in aqueous sodium hydroxide solution at $120^{\circ} \mathrm{C}$. The results revealed that PP extract was better than PCL extract for vanillic acid and vanillin production. Furthermore, the experiment also proved that large volume feeding was more efficient than small volume feeding for high vanillic acid and vanillin yield. Through large volume feeding, about $7 \pm 2 \mathrm{mg} \mathrm{L}^{-1}$ of vanillic acid and $5 \pm 1 \mathrm{mg} \mathrm{L}^{-1}$ of vanillin was successfully produced from PP extract via Aspergillus niger fermentation.
\end{abstract}

Keywords: Pineapple peel, Pineapple crown leaves, Vanillic acid, Vanillin, Ferulic acid, Bioconversion

\section{Introduction}

Pineapple is one of the main commodities in Malaysia. Its processing industry has been recognized as a highly potential industry by Ministry of Agriculture and Agrobased Industry of Malaysia (MOA). Pineapple industry is expected to expand at 5\% per annum following the consistent acceleration of pineapple production. The export value of pineapple industry was predicted to increase from RM 161 mil. in year 2015 to RM 258 mil. by the year of 2020 [1]. However, the development of the pineapple processing industry has simultaneously contributed to the accumulation of agricultural residues such as pineapple peel, crown leaves, core etc. In pineapple canneries,

\footnotetext{
*Correspondence: tangpl@tarc.edu.my

1 Department of Bioscience, Faculty of Applied Sciences, Tunku Abdul Rahman University College, Jalan Genting Kelang, Setapak, 53300 Kuala Lumpur, Malaysia

Full list of author information is available at the end of the article
}

nearly $75 \%$ of the fruits are discharged as waste [2]. The pineapple residues are commonly disposed by burning or decomposed due to the outdated technology and ignorance of the farmers and local entrepreneurs regarding the existence of commercial uses of pineapple residues [3]. Pineapple residues can be classified as on-farm waste such as leaves, stem, root remnants and processing waste such as core, peels, pulp etc. In overall, about 15.7-20.5 tonnes of total residues (dry basis) are generated following 12-18 tonnes pineapples processing [4]. Therefore, recycling of these potential lignocellulosic agricultural residues for the production of other value-added products is utterly needed to generate more revenues and overcome the environmental issues aroused from the improper by-products management in the industry.

Biotransformation of lignocellulosic by-products into vanillin by various fungi have been reported in several studies. Vanillin was reported being successfully

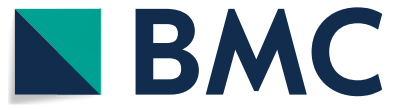

(c) The Author(s) 2020. This article is licensed under a Creative Commons Attribution 4.0 International License, which permits use, sharing, adaptation, distribution and reproduction in any medium or format, as long as you give appropriate credit to the original author(s) and the source, provide a link to the Creative Commons licence, and indicate if changes were made. The images or other third party material in this article are included in the article's Creative Commons licence, unless indicated otherwise in a credit line to the material. If material is not included in the article's Creative Commons licence and your intended use is not permitted by statutory regulation or exceeds the permitted use, you will need to obtain permission directly from the copyright holder. To view a copy of this licence, visit http://creativeco mmons.org/licenses/by/4.0/. The Creative Commons Public Domain Dedication waiver (http://creativecommons.org/publicdomain/ zero/1.0/) applies to the data made available in this article, unless otherwise stated in a credit line to the data. 
produced from rice bran oil, corn cob, wheat bran, sugar beet pulp etc. by either native fungus such as Aspergillus niger, Pycnoporus cinnabarinus, Pseudomonas fluorescens etc. or bacteria such as Escherichia coli JM109/pBB1, Bacillus aryabhattai BA03 [5-10]. According to Kaur and Chakraborty [11], vanillin can be synthesized from a wide range of compounds such as eugenol, glucose, tyrosine, capsaicin, isoeugenol etc. by applying different fungi, bacteria, plant cell or genetically engineered microorganism etc. Among the proposed compounds, lignin, eugenol, isoeugenol and ferulic acid are the most potential substrates.

Ferulic acid is the most abundant hydroxycinnamic acid in plant. In herbaceous plant, it is bonded to lignin and hemicellulose via ester and ether links. Due to its abundancy, research on the biotransformation of this compound into high value vanillin is still on-going [6, $12,13]$. Ferulic acid extraction procedures was evolved with the objective to maximize the recovery of ferulic acid yield from the complex structure of lignocellulose for the high yield production of vanillin and other value-added compounds [14-17]. In this study, pineapple peel (PP) and crown leaves (PCL) were selected due to its abundancy in the local agricultural industry and its high ferulic acid content [18].

Most native microorganism tends to accumulate/ excrete intermediate metabolites instead of vanillin during ferulic acid metabolism owing to the toxicity of vanillin towards cell metabolism. Nonetheless, basidiomycete such as $P$. cinnabarinus is more tolerant to vanillin [19]. However, ferulic acid polymerization reaction catalysed by the laccase enzyme secreted by $P$. cinnabarinus produces insoluble polymers during fermentation. In order to improve the vanillin yield, a two-pot bioconversion process of ferulic acid involving $A$. niger and $P$. cinnabarinus was initially proposed by LasegeMeessen et al. [20]. However, the previous research was conducted by using ferulic acid and vanillic acid standard solution. Therefore, it is of great interest to determine the potential of ferulic acid-containing pineapple residues extracts in the production of vanillic acid and vanillin by $A$. niger alone in this study.

In this study, ferulic acid of pineapple peel (PP) and pineapple crown leaves (PCL) was initially extracted by using aqueous $\mathrm{NaOH}$ solution. The yield and recovery of ferulic acid and non-ferulate phenolic compounds (NFPC) from both PP and PCL were optimized through centre composite response surface methodology (CCDRSM). The vanillic acid and vanillin production by $A$. niger I-1472 were studied at different feeding modes. Eventually, the best substrate was selected based on the yield of vanillic acid and vanillin.

\section{Materials and methods}

\section{Raw materials and fungal strain}

PP and PCL of Morris pineapple used were purchased from the local hypermarket in Kajang, Selangor, Malaysia. The PP and PCL were prepared from the same batch of pineapple with the species labelling. The fresh PP was oven-dried at $105^{\circ} \mathrm{C}$ for $12-14 \mathrm{~h}$ until the final moisture content reached approximately $5-8 \%$, whereas the fresh PCL was oven dried $\left(105^{\circ} \mathrm{C}\right)$ for $6-8 \mathrm{~h}$ until its moisture content reached at $8-11 \%$. Compositional analysis of PP and PCL was conducted according to the National Renewable Energy Laboratory (NREL) standard protocol [21-24]. The composition of PP and PCL were showed in Additional file 1: Appendix S1. The A. niger I-1472 strain was purchased from the Collection Nationale de Culture de Microorganisms (CNCM), Institut Pasteus, Paris, France. The strain was maintained on malt extract agar (contained $20 \mathrm{~g} \mathrm{~L}^{-1}$ malt extract and $15 \mathrm{~g} \mathrm{~L}^{-1}$ agar) at $-40{ }^{\circ} \mathrm{C}$. All other chemicals were analytical grade. Table 1.

\section{Aqueous alkaline treatment of PP and PCL}

Black liquor of PP and PCL was obtained by treating 4\% of PP and PCL respectively in $50 \mathrm{~g} \mathrm{~L}^{-1}$ aq. $\mathrm{NaOH}$ solution at $120{ }^{\circ} \mathrm{C}$ for an hour. Experiments were conducted in $500 \mathrm{~mL}$ Erlenmeyer flask in an autoclave. After the treatment, black liquor was separated from the residues by using muslin cloth under vacuum suction. All experiments were carried out in triplicate. The $\mathrm{pH}$ of the collected black liquor was adjusted to 2 by using concentrated sulphuric acid, followed by centrifugation at speed $1468 \times g$ for $5 \mathrm{~min}$ to recover the soluble lignin from the black liquor. Then, $\mathrm{pH}$ of the supernatant was adjusted to 5-6 by using calcium carbonate. Ferulic acid content in PP and PCL liquors was determined by using high performance liquid chromatography (HPLC), while total phenolic compounds content was determined through a modified Folin-Ciocalteau method [25].

Ferulic acid, vanillic acid and vanillin content were quantified using HPLC equipped with UV detector at wavelength $280 \mathrm{~nm}$ (Waters, Milford, USA). A $250 \mathrm{~mm} \times 4.6 \mathrm{~mm}$ HPLC column Gemini C18 (Phenomenex, California, USA) with $5 \mu \mathrm{m}$ particle size was used, and eluted using $0.1 \%$ acetic acid (solvent A) and methanol (solvent B) (Merck, Darmstadt, Germany). The mobile phase gradient was fixed at the ratio of 80:20 (A: B) from 0 to $24 \mathrm{~min}, 60: 40$ (A: B) from 24 to $27 \mathrm{~min}, 20: 80$ (A: B) from 27 to $36 \mathrm{~min}$, and 80:20 (A: B) from 36 to $40 \mathrm{~min}$. Flow rate of the analysis was fixed at

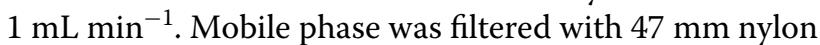
membrane with pore size $0.45 \mu \mathrm{m}$ and degassed. All the standards and samples were filtered through $0.22 \mu \mathrm{m}$ 
Table 1 Centre composite response surface experimental design [actual and coded value (in bracket)] of the optimization of ferulic acid and NFPC from the black liquor of (a) pineapple peel (PP) and (b) pineapple crown leaves (PCL)

\begin{tabular}{|c|c|c|c|c|c|}
\hline \multicolumn{6}{|c|}{ (a) Pineapple peel (PP) ${ }^{a}$} \\
\hline Solid content (\%) & Time (min) & $\begin{array}{l}\text { Ferulic acid yield } \\
\left(\mathrm{mg} \mathrm{L}^{-1}\right)\end{array}$ & $\begin{array}{l}\text { Ferulic acid recovery } \\
\left(\mathrm{mg} \mathrm{g}^{-1} \mathrm{PP}\right)\end{array}$ & $\begin{array}{l}\text { NFPC yield } \\
\left(\mathrm{mg} \mathrm{GAE} \mathrm{mL}^{-1}\right)\end{array}$ & $\begin{array}{l}\text { NFPC recovery } \\
\text { (mg GAE g }{ }^{-1} \text { PP) }\end{array}$ \\
\hline $12.00(0.000)$ & $105.00(0.000)$ & 486.80 & 4.06 & 3.91 & 32.59 \\
\hline $12.00(0.000)$ & $180.00(1.414)$ & 578.06 & 4.82 & 4.20 & 34.97 \\
\hline $6.34(-1.000)$ & $158.03(1.000)$ & 312.80 & 4.93 & 2.79 & 43.93 \\
\hline $17.66(1.000)$ & $158.03(1.000)$ & 401.05 & 2.27 & 4.15 & 23.51 \\
\hline $12.00(0.000)$ & $105.00(0.000)$ & 535.36 & 4.46 & 3.48 & 28.96 \\
\hline $4.00(-1.414)$ & $105.00(0.000)$ & 189.96 & 4.75 & 1.75 & 43.73 \\
\hline $20.00(1.414)$ & $105.00(0.000)$ & 639.08 & 3.20 & 4.06 & 20.31 \\
\hline $12.00(0.000)$ & $105.00(0.000)$ & 483.68 & 4.03 & 3.57 & 29.72 \\
\hline $12.00(0.000)$ & $105.00(0.000)$ & 546.18 & 4.55 & 3.60 & 29.97 \\
\hline $17.66(1.000)$ & $51.97(-1.000)$ & 634.65 & 3.60 & 4.50 & 25.46 \\
\hline $6.34(-1.000)$ & $51.97(-1.000)$ & 36.99 & 0.58 & 2.28 & 35.88 \\
\hline $12.00(0.000)$ & $30.00(-1.414)$ & 190.52 & 1.59 & 3.60 & 29.97 \\
\hline $12.00(0.000)$ & $105.00(0.000)$ & 527.93 & 4.40 & 3.25 & 27.09 \\
\hline \multicolumn{6}{|c|}{ (b) Pineapple crown leaves (PCL) } \\
\hline Solid content (\%) & Time $(\min )$ & $\begin{array}{l}\text { Ferulic acid yield } \\
\left(\mathrm{mg} \mathrm{L}^{-1}\right)\end{array}$ & $\begin{array}{l}\text { Ferulic acid recovery } \\
\left(\mathrm{mg} \mathrm{g}^{-1} \mathrm{PCL}\right)\end{array}$ & $\begin{array}{l}\text { NFPC yield } \\
\left(\mathrm{mg} \mathrm{GAE} \mathrm{mL}^{-1}\right)\end{array}$ & $\begin{array}{l}\text { NFPC recovery } \\
\left.\text { ( } \mathrm{mg} \mathrm{GAE} \mathrm{g}^{-1} \mathrm{PCL}\right)\end{array}$ \\
\hline $6.00(0.000)$ & $105.00(0.000)$ & 184.55 & 3.08 & 2.96 & 49.30 \\
\hline $6.00(0.000)$ & $180.00(1.414)$ & 165.28 & 2.75 & 2.83 & 47.24 \\
\hline $6.00(0.000)$ & $105.00(0.000)$ & 175.00 & 2.92 & 3.28 & 54.69 \\
\hline $8.83(1.000)$ & $158.03(1.000)$ & 249.89 & 2.83 & 3.79 & 42.87 \\
\hline $2.00(-1.414)$ & $105.00(0.000)$ & 9.48 & 0.47 & 1.15 & 57.57 \\
\hline $6.00(0.000)$ & $105.00(0.000)$ & 173.36 & 2.89 & 3.08 & 51.36 \\
\hline $6.00(0.000)$ & $105.00(0.000)$ & 160.54 & 2.68 & 2.91 & 48.51 \\
\hline $6.00(0.000)$ & $105.00(0.000)$ & 165.00 & 2.75 & 2.98 & 49.62 \\
\hline $6.00(0.000)$ & $30.00(-1.414)$ & 201.26 & 3.35 & 2.86 & 47.72 \\
\hline $8.83(1.000)$ & $51.97(-1.000)$ & 263.85 & 2.99 & 3.79 & 42.87 \\
\hline $3.17(-1.000)$ & $51.97(-1.000)$ & 28.10 & 0.89 & 1.61 & 50.72 \\
\hline $3.17(-1.000)$ & $158.03(1.000)$ & 141.40 & 4.46 & 1.78 & 56.12 \\
\hline $10.00(1.414)$ & $105.00(0.000)$ & 311.67 & 3.12 & 3.73 & 37.28 \\
\hline
\end{tabular}

${ }^{a} \mathrm{mg} \mathrm{GAE} \mathrm{mL}^{-1}$ and $\mathrm{mg} \mathrm{GAE} \mathrm{g}^{-1} \mathrm{PP}$ means milligram of gallic acid equivalent per milliliter of extract and milligram of gallic acid equivalent per gram of pineapple peel respectively

b $\mathrm{mg} \mathrm{GAE} \mathrm{mL}^{-1}$ and $\mathrm{mg} \mathrm{GAE} \mathrm{g}^{-1}$ PP means milligram of gallic acid equivalent per milliliter of extract and milligram of gallic acid equivalent per gram of pineapple crown leaves respectively

nylon membrane prior to analysis. Vanillic acid, vanillin and ferulic acid purchased from Sigma Aldrich, Missouri, USA were used as the reference standards. Quantitative analysis was carried out by using caffeine (Sigma Aldrich, Missouri, USA) as an internal standard. Analysis was conducted with an injection volume of $10 \mu \mathrm{L}$ and data acquisition was carried out with Breeze software (Waters, Milford, USA).

For total phenolic content (TPC) analysis, about $0.5 \mathrm{~mL}$ of $0.2 \mathrm{~N}$ Folin-Ciocalteau reagent (Merck, Darmstdt, Germany) was added into $0.1 \mathrm{~mL}$ aliquot. After $5 \mathrm{~min}$ conditioning at room temperature, about $0.4 \mathrm{~mL}$ of $75 \mathrm{~g} \mathrm{~L}^{-1}$ sodium carbonate solution (Merck, Darmstdt, Germany) was added, and the volume of the mixture was made up to $5 \mathrm{~mL}$ with distilled water. The mixture was then let to condition at room temperature in dark for $2 \mathrm{~h}$. Absorbance of the mixture was determined spectrophotometrically at $760 \mathrm{~nm}$ using VERSAmax ELISA microplate reader coupled with SOFTmax Pro software (Molecular Devices, California, USA). TPC of the black liquor was quantified based on the constructed calibration curve using gallic acid (Sigma Aldrich, Missouri, 
USA) as the reference. Concentration of TPC was expressed as $\mathrm{mg}$ gallic acid equivalent per $\mathrm{mL}$ of liquor $\left(\mathrm{mg} \mathrm{GAE} \mathrm{mL}^{-1}\right)$.

To determine the non-ferulate phenolic compounds (NFPC), the amount of ferulic acid (in $\mathrm{mg}$ GAE $\mathrm{mL}^{-1}$ ) was subtracted from the amount of TPC in the liquor. A series concentration of ferulic acid standard solutions and the samples were quantified by using HPLC (in $\mathrm{mg} \mathrm{L}^{-1}$ ) and VERSAmax ELISA microplate reader (in mg GAE $\mathrm{mL}^{-1}$ ) respectively. The unit conversion curve of ferulic acid standard in unit $\mathrm{mg} \mathrm{mL}^{-1}$ versus ferulic acid in unit $\mathrm{mg}$ GAE $\mathrm{mL}^{-1}$ was constructed. This conversion curve was then used to calculate the ferulic acid concentration of the samples in unit $\mathrm{mg} \mathrm{GAE} \mathrm{mL}^{-1}$.

\section{Optimization of ferulic acid and non-ferulate phenolic compounds (NFPC) production from PP and PCL}

Ferulic acid yield from PP and PCL was optimized through central composite design (CCD) with 5 levels and 2 variables using Design Expert 6.0.10 software (StatEase Inc., Minneapolis, USA). The effects of substrate concentration $\left(\mathrm{X}_{1}\right)$ and treatment time $\left(\mathrm{X}_{2}\right)$ on ferulic acid yield $\left(\mathrm{Y}_{1}\right)$, ferulic acid recovery $\left(\mathrm{Y}_{2}\right)$, NFPC yield $\left(\mathrm{Y}_{3}\right)$ and NFPC recovery $\left(\mathrm{Y}_{4}\right)$ were evaluated. The PP and PCL were treated in $50 \mathrm{~g} \mathrm{~L}^{-1}$ aq. $\mathrm{NaOH}$ solution at different substrate concentrations and times in an autoclave at $120^{\circ} \mathrm{C}$. The experimental design of ferulic acid extraction from PP and PCL is shown in Table $1 \mathrm{a}, \mathrm{b}$ respectively. The polynomial models were developed to describe the relationship between the experimental variables $\left(\mathrm{X}_{1}\right.$ and $\left.\mathrm{X}_{2}\right)$ and responses $\left(\mathrm{Y}_{1}, \mathrm{Y}_{2}, \mathrm{Y}_{3}\right.$ and $\left.\mathrm{Y}_{4}\right)$. The optimum condition for maximum yield was predicted by integrating the constructed polynomial models. The main and interaction effects of the variables on the responses were evaluated based on the significance level of the regression coefficient in the model.

Because of the experiment limitation in lignin removal for black liquor produced from the treatment at higher solid content, ethyl acetate had been used as the ferulic acid extraction solvent. The failure in complete lignin removal from the produced liquor prevented it from HPLC analysis. An equal volume of ethyl acetate was added to the neutralized liquor, and shake vigorously at room temperature to recover the ferulic acid from liquor. The separation of these two layers was carried out under centrifugation at speed $1468 \times g$ for $3 \mathrm{~min}$. The upper layer (ethyl acetate layer) was collected, and dried under vacuum using rotatory evaporator. The phenolic compounds were observed as the yellowish undissolved layer at the bottom of flask. The $50 \% \mathrm{v} / \mathrm{v}$ ethanol solution was then added to dissolve these compounds, followed by HPLC analysis according to protocol described in part 2.2 .
Ferulic acid extraction with ethyl acetate was optimized using the black liquor produced from the optimized treatment. The extraction was repeated for two to three times by using an equal volume of ethyl acetate with the black liquor.

\section{Fermentation of PP and PCL extracts}

Aspergillus niger I-1472 was grown on malt extract agar (contained $20 \mathrm{~g} \mathrm{~L}^{-1}$ malt extract and $15 \mathrm{~g} \mathrm{~L}^{-1}$ agar) at $30{ }^{\circ} \mathrm{C}$. The spores were harvested after 1 week of growth. About $1 \mathrm{~mL}$ of spore suspension (at concentration of $10^{6}-10^{7} \mathrm{cfu} \mathrm{mL} \mathrm{m}^{-1}$ ) was inoculated into $100 \mathrm{~mL}$ basal medium containing $20 \mathrm{~g} \mathrm{~L}^{-1}$ maltose, $1.8 \mathrm{~g} \mathrm{~L}^{-1}$ diammonium tartrate, $0.5 \mathrm{~g} \mathrm{~L}^{-1}$ yeast extract, $0.5 \mathrm{~g} \mathrm{~L}^{-1}$ magnesium sulphate, $0.2 \mathrm{~g} \mathrm{~L}^{-1}$ dipotassium hydrogen phosphate and $0.013 \mathrm{~g} \mathrm{~L}^{-1}$ calcium chloride. The $\mathrm{pH}$ of medium was initially adjusted to 5 . A. niger I-1472 was incubated at $30{ }^{\circ} \mathrm{C}$ for 3 days with agitation at $150 \mathrm{rpm}$ $[26,27]$. About $0.5 \mathrm{~mL}$ of the neutralized PP and PCL liquors were fed daily to $A$. niger from day 3 until day 6 . The medium was filtered with Whatman no. 1 filter paper at the end of fermentation to separate the cell pellets. Vanillic acid, vanillin and ferulic acid residue in the medium after fermentation were quantified by using HPLC as the described protocol in part 2.2.

The effect of liquor feeding modes, namely large volume feeding (LVF) and small volume feeding (SVF) on the vanillic acid and vanillin yield was investigated. For LVF, about $10 \mathrm{~mL}$ of PP and PCL liquor respectively was fed on day 3 and day 4 . Prior to feeding, about $20 \mathrm{~mL}$ of medium was removed. The fermentation was stopped on day 5 by separating the cell pellets from fermentation medium through filtration. For SVF, about $1.5 \mathrm{~mL}$ of PP and PCL liquor respectively was fed daily from day 3 to day 6 . Prior to feeding, about $6 \mathrm{~mL}$ of medium was removed. The fermentation was stopped on day 7 . The fermentation control was fed with $300 \mathrm{mg} \mathrm{L}^{-1}$ and $1000 \mathrm{mg} \mathrm{L}^{-1}$ ferulic acid standard solution. Vanillic acid, vanillin and ferulic acid contents were determined using HPLC.

All experiments were conducted in triplicates. The results are expressed as mean \pm standard deviation. The significant differences between the means were determined through one-way ANOVA, followed by Duncan post hoc test at $95 \%$ confidence interval using SPSS software version 20 (IBM Corporation, USA).

\section{Results and discussion}

\section{Ferulic acid extraction}

Alkaline treatment of PP and PCL with $50 \mathrm{~g} \mathrm{~L}^{-1} \mathrm{NaOH}$ at $120^{\circ} \mathrm{C}$ for an hour successfully yields $202 \pm 18 \mathrm{mg} \mathrm{L}^{-1}$ and $120 \pm 11 \mathrm{mg} \mathrm{L}^{-1}$ ferulic acid respectively. PP was initially proved as the best source of ferulic acid, where 
$5 \mathrm{mg}$ of ferulic acid was produced from each gram of PP (in dry basis), while only $3 \mathrm{mg}$ of ferulic acid was produced from each gram of PCL (in dry basis). Beside ferulic acid, other phenolic compounds were also extracted into the black liquor during alkaline treatment. About $0.74 \pm 0.02 \mathrm{mg} \mathrm{GAE} \mathrm{mL}^{-1}$ (with the recovery of $18.4 \pm 0.6 \mathrm{mg} \mathrm{GAE} \mathrm{g}^{-1} \mathrm{PP}$ ) and $0.66 \pm 0.09 \mathrm{mg} \mathrm{GAE} \mathrm{mL}^{-1}$ (with a recovery of $17 \pm 2 \mathrm{mg} \mathrm{GAE} \mathrm{g}^{-1} \mathrm{PCL}$ ) of NFPC had been extracted from PP and PCL respectively.

As reported by Buranov and Mazza [12], hydroxycinnamic derivatives such as $p$-coumaric acid and ferulic acid are attached to the lignin and hemicellulose via ester and ether bonds as a bridge in the herbaceous plant. Evidence of the esterification of ferulic acid to hemicellulose of pineapple cell wall was also reported by Smith and Harris [28]. In order to release these valuable components from the lignin/phenolics-carbohydrate complexes of the pineapple residues, alkaline solvent was chosen in this study. During alkaline hydrolysis, the alkali cleaves the ester bond of ferulate bridge, liberating the ferulic acid and lignin from the hemicellulose. Among various alkaline available, sodium hydroxide had been selected because it was reported to be more selective in the released of phenolic compounds [29].

As reported in this study, ferulic acid extracted from PP was higher than PCL. This finding can be explained by the differences in hemicellulose and lignin contents of PP and PCL (shown in Additional file 1: Appendix S1). As ferulic acid is presence as ferulate bridge in the lignincarbohydrate structure, we strongly believed that there is a relationship between the ferulic acid content and hemicellulose and lignin content of the pineapple residues. Both hemicellulose and lignin content of PP is higher than PCL. Thus, PP was expected to contain higher ferulic acid.

In addition, the initial finding from a fermentation study on the black liquor by $A$. niger suggested that the production of vanillic acid was mainly due to the conversion of ferulic acid. Ferulic acid was disappeared while other unknown NFPCs were detected after fermentation. About $1.05 \pm 0.05 \mathrm{mg} \mathrm{L}^{-1}$ (at molar conversion of $9 \%$ ) and $0.5 \pm 0.1 \mathrm{mg} \mathrm{L}^{-1}$ (at molar conversion of $7 \%$ ) of vanillic acid had produced from the fermentation of neutralized PP and PCL liquor respectively. Biotransformation of ferulic acid by $A$. niger I-1472 into vanillic acid, prior to vanillin production by Pcynoporus cinnabarinus MUCL 39533 is a well-known fermentation process by Lesage-Meessen et al. [20]. In their study, the productivity of vanillic acid was reported at molar conversion of $88 \%$ with the feeding of $300 \mathrm{mg} \mathrm{L}^{-1}$ ferulic acid. However, the productivity of vanillic acid from the black liquor of pineapple residues was not as efficient as those fed with the ferulic acid standard solution. The lower molar conversion rate of ferulic acid in the fermentation of pineapple residues black liquors was suspected due to some extent of inhibition by the unknown NFPC and other toxic compounds, as well as the lower concentration of ferulic acid in the liquors. Therefore, in order to optimize the productivity of vanillic acid, optimization of ferulic acid yield from the pineapple residues and the study on the effects of feeding modes on the efficiency of fermentation were carried out in the following study.

\section{Optimization of ferulic acid and NFPC extraction}

The ferulic acid and NFPC yield and recovery from PP and PCL through different treatment conditions were showed in Table 1a, b. The influences of each variable $\left(\mathrm{X}_{1}\right.$ : substrate concentration; $\mathrm{X}_{2}$ : treatment time) on the responses $\left(\mathrm{Y}_{1}\right.$ : ferulic acid yield; $\mathrm{Y}_{2}$ : ferulic acid recovery; $Y_{3}$ : NFPC yield; $Y_{4}$ : NFPC recovery) were explained by the developed regression models (as shown in Additional file 2: Appendix S2).

Table 2a, b showed the results of regression analysis on the regression coefficient of the models. Based on the results, most of the regression coefficient that explained the relationship between variables $\left(\mathrm{X}_{1}\right.$ and $\left.\mathrm{X}_{2}\right)$, and responses $\left(\mathrm{Y}_{1}, \mathrm{Y}_{2}, \mathrm{Y}_{3}\right.$ and $\left.\mathrm{Y}_{4}\right)$ were significant $(p<0.05)$ for both substrate PP and PCL. Besides, the interaction of $\mathrm{X}_{1} \mathrm{X}_{2}$ also showed significant $(p<0.05)$ for both $\mathrm{Y}_{1}$ and $\mathrm{Y}_{2}$. In addition, the results also indicated that all regression coefficients of variable $\mathrm{X}_{1}$ were significant $(p<0.05)$ for the model that explained NFPC yield and recovery, but not for variable $\mathrm{X}_{2}$. Therefore, this finding confirmed that the substrate concentration $\left(\mathrm{X}_{1}\right)$ exerted a stronger effect than treatment time $\left(\mathrm{X}_{2}\right)$ in the extraction of NFPC. These findings were supported by a similar study reported by Torre et al. [29], where the amount of ferulic acid released from the corn cobs was reported to increase following the increase of solid: liquid ratio in the treatment. Moreover, the ferulic acid and NFPC yield were also found to increase to a larger extent under high substrate treatment, compared to the long-time treatment.

However, the recovery of ferulic acid from PP and NFPC recovery from both PP and PCL were reduced with the increase of substrate concentration. Compounds (ferulic acid and NFPC) saturation in the solvent during treatment at high solid: liquid ratio was strongly believed to be the main factor that caused the reduction of ferulic acid and NFPC recovery. Nonetheless, this condition was not observed for PCL. This finding suggested that the substrate and ferulic acid saturation phenomenon did not occur in the PCL treatment. The lower substrate concentration $(2-10 \%)$ and ferulic acid availability in PCL were probably the factors that prevent substrate and ferulic acid saturation phenomenon during PCL treatment. In spite of that, Mussatto et al. [30] reported that treatment 
Table 2 Regression analysis on the regression coefficient of polynomial models that explaine the influences of substrate concentration $\left(X_{1}\right)$ and treatment time $\left(X_{2}\right)$ on the yield and recovery of ferulic acid and NFPC from (a) pineapple peel (PP) and (b) pineapple crown leaves (PCL)

\begin{tabular}{|c|c|c|c|c|c|c|c|c|}
\hline \multicolumn{9}{|c|}{ (a) Pineapple peel (PP) } \\
\hline \multirow[t]{3}{*}{ Coefficient } & \multicolumn{4}{|l|}{ Ferulic acid } & \multicolumn{4}{|l|}{ NFPC } \\
\hline & \multicolumn{2}{|l|}{ Yield } & \multicolumn{2}{|l|}{ Recovery } & \multicolumn{2}{|l|}{ Yield } & \multicolumn{2}{|l|}{ Recovery } \\
\hline & Coefficient $^{a}$ & $p$-value ${ }^{\text {b }}$ & Coefficient $^{a}$ & $p$-value ${ }^{b}$ & Coefficient $^{a}$ & $p$-value $^{\mathbf{b}}$ & Coefficient $^{\mathrm{a}}$ & $p$-value ${ }^{\mathbf{b}}$ \\
\hline \multicolumn{9}{|l|}{ Linear } \\
\hline$\beta_{1}$ & +184.17 & 0.01 & +0.72 & 0.27 & +0.86 & $<0.00$ & -7.99 & $<0.00$ \\
\hline$\beta_{2}$ & -115.91 & 0.06 & +0.37 & 0.55 & +0.13 & 0.13 & +1.65 & 0.02 \\
\hline \multicolumn{9}{|l|}{ Quadratic } \\
\hline$\beta_{11}$ & -64.00 & 0.01 & -0.35 & 0.13 & -0.32 & $<0.00$ & +1.16 & 0.09 \\
\hline$\beta_{22}$ & -79.11 & $<0.00$ & -0.73 & 0.01 & +0.17 & 0.06 & +1.39 & 0.05 \\
\hline \multicolumn{9}{|l|}{ Cubic } \\
\hline$\beta_{111}$ & -12.69 & 0.69 & -0.64 & 0.14 & - & - & - & - \\
\hline$\beta_{222}$ & +126.47 & 0.01 & +0.38 & 0.34 & - & - & - & - \\
\hline \multicolumn{9}{|l|}{ Interaction } \\
\hline$\beta_{12}$ & -127.35 & $<0.00$ & -1.42 & $<0.00$ & -0.21 & 0.08 & -2.50 & 0.01 \\
\hline \multicolumn{9}{|c|}{ (b) Pineapple crown leaves (PCL) } \\
\hline \multirow[t]{3}{*}{ Coefficient } & \multicolumn{4}{|l|}{ Ferulic acid } & \multicolumn{4}{|l|}{ NFPC } \\
\hline & \multicolumn{2}{|l|}{ Yield } & \multicolumn{2}{|l|}{ Recovery } & \multicolumn{2}{|l|}{ Yield } & \multicolumn{2}{|l|}{ Recovery } \\
\hline & Coefficient $^{\mathrm{a}}$ & $p$-value ${ }^{b}$ & Coefficient $^{a}$ & $p$-value ${ }^{b}$ & Coefficient $^{\mathrm{a}}$ & $p$-value ${ }^{b}$ & Coefficient $^{a}$ & $p$-value ${ }^{b}$ \\
\hline \multicolumn{9}{|l|}{ Linear } \\
\hline$\beta_{1}$ & +65.28 & $<0.00$ & -0.70 & 0.07 & +0.98 & $<0.00$ & -6.23 & $<0.00$ \\
\hline$\beta_{2}$ & +62.39 & $<0.00$ & +1.92 & $<0.00$ & +0.02 & 0.76 & +0.59 & 0.49 \\
\hline \multicolumn{9}{|l|}{ Quadratic } \\
\hline$\beta_{11}$ & -5.84 & 0.13 & -0.44 & 0.01 & -0.28 & $<0.00$ & -1.46 & 0.14 \\
\hline$\beta_{22}$ & +5.51 & 0.14 & +0.19 & 0.13 & -0.07 & 0.23 & -1.44 & 0.14 \\
\hline \multicolumn{9}{|l|}{ Cubic } \\
\hline$\beta_{111}$ & +20.78 & 0.02 & +0.82 & 0.01 & - & - & - & - \\
\hline$\beta_{222}$ & -37.55 & $<0.00$ & -1.07 & $<0.00$ & - & - & - & - \\
\hline \multicolumn{9}{|l|}{ Interaction } \\
\hline$\beta_{12}$ & -31.82 & $<0.00$ & -0.93 & $<0.00$ & -0.04 & 0.57 & -1.35 & 0.28 \\
\hline
\end{tabular}

Note: ${ }^{a}$ Coefficient indicates the regression constant of the linear, quadratic, cubic and interaction terms in the polynomial equation that explain the relationship between substrate concentration $\left(X_{1}\right)$ and treatment time $\left(X_{2}\right)$ with the yield and recovery of ferulic acid $\left(Y_{1}, Y_{2}\right)$ and NFPC $\left(Y_{3}, Y_{4}\right)$

b $p$-value lower than 0.05 indicate that the effect of the term on the yield and recovery of ferulic acid and NFPC are significant at $95 \%$ confidence interval. $p$-value lower than 0.01 indicate that the effect of the term on the yield and recovery of ferulic acid and NFPC are significant at $99 \%$ confidence interval

time exerted stronger effect in improving ferulic acid yield than other phenolic compounds such as coumaric acid. The efficiency of a treatment to release phenolic compounds from lignin/phenolic-carbohydrate complex is strongly affected by the types and properties of chemical bonds in the structure [12,31]. Therefore, due to the involvement of several types of chemical debonding during NFPC release, the NFPC extraction efficiency was least affected by the treatment time. Compared to NFPC extraction, ferulic acid extraction probably involved a more specific cleavage of chemical linkages.
The validity of the obtained regression models was analysed statistically by ANOVA. The insignificant lack of fit $(p>0.05)$ and high $\mathrm{R}^{2}$-value $\left(\mathrm{r}^{2}>0.90\right)$ of the regression models suggested that the trend of changes of ferulic acid and NFPC yield and recovery from PP and PCL through different treatment condition can be wellexplained by these regression equations. Thus, an optimum treatment condition with the highest ferulic acid and NFPC yield and recovery were predicted by using these regression equations. The optimum conditions for maximum ferulic acid and NFPC yield and recovery 
from PP and PCL were successfully obtained by integrating the regression equations. Upon optimization of PP, about $728 \mathrm{mg} \mathrm{L}^{-1}$ of ferulic acid (with the recovery of $4 \mathrm{mg} \mathrm{g}^{-1} \mathrm{PP}$ ) and $5 \mathrm{mg} \mathrm{GAE} \mathrm{mL}{ }^{-1}$ of NFPC (with recovery of $23 \mathrm{mg} \mathrm{GAE} \mathrm{g}^{-1} \mathrm{PP}$ ) were predicted by treating $19.3 \%$ of $\mathrm{PP}$ in $50 \mathrm{~g} \mathrm{~L}^{-1} \mathrm{NaOH}$ aqueous solution at $120{ }^{\circ} \mathrm{C}$ for $76 \mathrm{~min}$. These predictions were successfully verified within $95 \%$ confidence interval with the detection of $766 \pm 37 \mathrm{mg} \mathrm{L}^{-1}$ of ferulic acid (with recovery of $4.0 \pm 0.2 \mathrm{mg} \mathrm{g}^{-1} \mathrm{PP}$ ) and $4.9 \pm 0.2 \mathrm{mg} \mathrm{GAE} \mathrm{mL}^{-1}$ of NFPC (with recovery of $25 \pm 1 \mathrm{mg} \mathrm{GAE} \mathrm{mL}^{-1}$ ) in the validation experiment.

Meanwhile, upon the treatment of $9.9 \%$ of PCL in $50 \mathrm{~g} \mathrm{~L}^{-1} \mathrm{NaOH}$ aqueous solution at $120^{\circ} \mathrm{C}$ for $36 \mathrm{~min}$, about $369 \mathrm{mg} \mathrm{L}^{-1}$ of ferulic acid (with the recovery of $5 \mathrm{mg} \mathrm{g}^{-1} \mathrm{PCL}$ ) and $4 \mathrm{mg} \mathrm{GAE} \mathrm{mL}{ }^{-1}$ of NFPC (with the

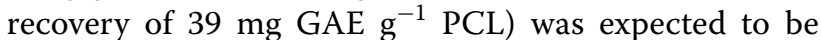
produced. This prediction was also successfully verified within $95 \%$ confidence interval where $328 \pm 23 \mathrm{mg} \mathrm{L}^{-1}$ of ferulic acid (with recovery of $3.3 \pm 0.2 \mathrm{mg} \mathrm{g}^{-1} \mathrm{PCL}$ ) and $3.1 \pm 0.3 \mathrm{mg} \mathrm{GAE} \mathrm{mL}^{-1}$ of NFPC (with recovery of $32 \pm 3 \mathrm{mg} \mathrm{GAE} \mathrm{g}^{-1} \mathrm{PCL}$ ) were produced under this optimum condition.

Furthermore, the results of ferulic acid extraction using ethyl acetate showed that an equal volume of ethyl acetate extraction must carried out twice on PP liquor for complete ferulic acid extraction. About $1055 \pm 160 \mathrm{mg} \mathrm{L}^{-1}$ of ferulic acid (with the recovery of $5.5 \pm 0.8 \mathrm{mg} \mathrm{g}^{-1} \mathrm{PP}$ ) was successfully extracted. For PCL liquor which contained lower ferulic acid, single extraction by using an equal volume of ethyl acetate with the PCL liquor was sufficient for complete ferulic acid extraction.
Our results of this study revealed that RSM optimization improved the yield and recovery of ferulic acid and NFPC from PP and PCL significantly $(p<0.05)$. For PP, the ferulic acid yield and recovery had been improved approximately $423 \%$ and $8 \%$ respectively; while NFPC yield and recovery had improved $555 \%$ and $37 \%$ respectively after optimum treatment. While, the ferulic acid yield and recovery from PCL was also improved by about $174 \%$ and $11 \%$ respectively; whereas the NFPC yield and recovery were improved by $373 \%$ and $92 \%$ respectively after the optimum treatment. Furthermore, the improvement of ferulic acid extraction in this study was proven more effective than the previous study by Noor-Hasyierah et al. [32]. In their study by using substrate paddy straw, ferulic acid improvement after RSM optimization only achieved about $37 \%$. Because of the ferulic acid and NFPC content of the black liquor determine its potential as a feedstock for vanillic acid (as well as vanillin) production in fermentation, optimization process became a crucial part in this study.

\section{Fermentation of PP and PCL liquor}

Table 3 showed the yield and molar conversion of vanillic acid and vanillin from the PP and PCL liquors fermentation at two different feeding modes. The findings suggested that the vanillic acid and vanillin yield were significantly $(p<0.05)$ affected by the interplay between feeding modes and ferulic acid content of the feeding liquor. LVF contributed to higher vanillic acid and vanillin yield, compared to SVF. Fermentation of PP liquor which containing higher ferulic acid content produced higher vanillin yield $\left(5 \pm 1 \mathrm{mg} \mathrm{L}^{-1}\right)$ than PCL liquor via LVF. Yet, the vanillic acid yield produced from the fermentation

Table 3 Yield and molar conversion of the vanillic acid and vanillin from the fermentation of PP and PCL liquor in two different feeding modes $(n=3)$

\begin{tabular}{|c|c|c|c|c|c|c|}
\hline \multirow[t]{2}{*}{ Product } & & & \multicolumn{2}{|c|}{ Small volume feeding } & \multicolumn{2}{|c|}{ Large volume feeding } \\
\hline & & & PP liquor & PCL liquor & PP liquor & PCL liquor \\
\hline \multirow[t]{4}{*}{ Ferulic acid } & Feed ( $\mu \mathrm{mol})$ & & $33 \pm 5$ & $10.1 \pm 0.7$ & $109 \pm 17$ & $34 \pm 2$ \\
\hline & Consumed ( $\mu \mathrm{mol})$ & & 33 & 10.1 & 48 & 18.4 \\
\hline & Remained & $\mathrm{mg} \mathrm{L}^{-1}$ & $n / d$ & $n / d$ & $117 \pm 10$ & $30 \pm 1$ \\
\hline & & $\mu \mathrm{mol}$ & $<0.00$ & $<0.00$ & $60 \pm 5$ & $15.4 \pm 0.5$ \\
\hline \multirow[t]{3}{*}{ Vanillic acid } & Yield $^{a}$ & $\mathrm{mg} \mathrm{L}^{-1}$ & $4 \pm 2$ & $0.9 \pm 0.1$ & $7 \pm 2$ & $6 \pm 1$ \\
\hline & & $\mu \mathrm{mol}$ & $2.6 \pm 0.9$ & $0.52 \pm 0.07$ & $3.8 \pm 0.9$ & $3.8 \pm 0.7$ \\
\hline & Molar conversion (\%) & & 7.9 & 5.1 & 7.9 & 20.7 \\
\hline \multirow[t]{3}{*}{ Vanillin } & Yield $^{a}$ & $\mathrm{mg} \mathrm{L}^{-1}$ & $n / d$ & $0.8 \pm 0.1$ & $5 \pm 1$ & $2.5 \pm 0.2$ \\
\hline & & $\mu \mathrm{mol}$ & $n / d$ & $0.51 \pm 0.06$ & $3 \pm 0.8$ & $1.6 \pm 0.2$ \\
\hline & Molar conversion (\%) ${ }^{\mathrm{b}}$ & & $n / d$ & 0.5 & 6.3 & 8.9 \\
\hline
\end{tabular}

$n / d$ not detected

a Yield indicates the concentration $\left(\mathrm{mg} \mathrm{L}^{-1}\right)$ of vanillic acid/vanillin produced from A. niger fermentation

b Molar conversion indicates the percentage of vanillic acid/vanillin molar yield produced from the molar consumption of ferulic acid during $A$. niger fermentation 
of PP and PCL liquor had no significant difference $(p>0.05)$. Nevertheless, trace vanillin $\left(0.8 \pm 0.1 \mathrm{mg} \mathrm{L}^{-1}\right)$ was detected in the fermentation of PCL liquor at SVF, but not for PP liquor. In the SVF fermentation of PP liquor, vanillic acid $\left(4 \pm 2 \mathrm{mg} \mathrm{L}^{-1}\right)$ was the only fermentation product. Furthermore, ferulic acid was completely consumed by $A$. niger in the SVF fermentation, but not for LVF. A large amount of unconsumed ferulic acid has been detected in the medium after LVF fermentation.

Although the vanillin yield from LVF fermentation of PCL liquor $\left(2.5 \pm 0.2 \mathrm{mg} \mathrm{L}^{-1}\right)$ was lower than those fed with PP liquor ( $\left.5 \pm 1 \mathrm{mg} \mathrm{L}^{-1}\right)$, its ferulic acid molar conversion was comparatively high. In LVF fermentation, only $45 \%$ and $54 \%$ of the total ferulic acid in the PP and PCL liquor respectively had been consumed. The molar conversion of vanillic acid and vanillin achieved $20.7 \%$ and $8.9 \%$ respectively during PCL liquor fermentation, while the molar conversion of vanillic acid and vanillin from ferulic acid in PP liquor was only about $7.9 \%$ and $6.3 \%$ respectively. These results unveiled that PCL liquor had better fermentability than PP liquor. Nevertheless, PP liquor was a better substrate than PCL liquor for higher vanillin yield. Based on these findings, our initial hypothesis that propose the interplay between feeding modes and ferulic acid concentration on the yield and molar conversion of vanillic acid and vanillin in A. niger fermentation was supported. In addition, the molar conversion of vanillic acid from PP liquor in both SVF and LVF was insignificant $(p>0.05)$. However, the molar conversion of vanillic acid of PCL liquor was increased fourfold when the feeding mode was changed from SVF to LVF.

Table 4 showed the comparison of vanillic acid yield and its molar conversion in the fermentation fed with ferulic acid standard solution, PP and PCL liquors. The results obtained indicated that only fermentation fed with PP and PCL liquors produced vanillin. Nonetheless, the vanillic acid yield and molar conversion in the fermentation of PCL liquor was higher than with fermentation of $300 \mathrm{mg} \mathrm{L}^{-1}$ ferulic acid standard solution. On the other hand, the vanillic acid yield and molar conversion in the fermentation of PP liquor was lower than with fermentation of $1000 \mathrm{mg} \mathrm{L}^{-1}$ ferulic acid standard solution. This finding suggests that the NFPC content in the liquors of PP and PCL significantly affects the vanillic acid and vanillin production by $A$. niger. The interplay of the feeding modes, ferulic acid and NFPC concentration was strongly believed to be the factor that contributed to this observation, possibly by an effect on the metabolic pathway of $A$. niger.

PP liquor contained higher ferulic acid and NFPC content than PCL liquor. Therefore, the impact of NFPC on the fermentability of PP liquor was likely stronger than
Table 4 Vanillic acid yield and its molar conversion during the fermentation of ferulic acid standard solution and liquors of pineapple residues (PP and $P C L)(n=3)$

\begin{tabular}{lll}
\hline Substrate & Yield $\left(\mathbf{m g ~ L}^{-\mathbf{1}}\right)^{\mathbf{a}}$ & $\begin{array}{l}\text { Molar } \\
\text { conversion } \\
(\%))^{\mathbf{b}}\end{array}$ \\
\hline Small volume feeding & \\
$300 \mathrm{mg} \mathrm{L}^{-1}$ ferulic acid & $<0.00$ & 0 \\
PCL liquor & $0.9 \pm 0.1$ & 5.1 \\
$1000 \mathrm{mg} \mathrm{L}^{-1}$ ferulic acid & $5.8 \pm 0.7$ & 11.2 \\
PP liquor & $4 \pm 2$ & 7.9 \\
Large volume feeding & & \\
$300 \mathrm{mg} \mathrm{L}^{-1}$ ferulic acid & $3.9 \pm 0.7$ & 8.2 \\
PCL liquor & $6 \pm 1$ & 20.7 \\
$1000 \mathrm{mg} \mathrm{L}^{-1}$ ferulic acid & $15 \pm 2$ & 11.2 \\
PP liquor & $7 \pm 2$ & 7.9 \\
\hline
\end{tabular}

a Yield indicates the concentration $\left(\mathrm{mg} \mathrm{L}^{-1}\right)$ of vanillic acid/vanillin produced after A. niger fermentation

${ }^{\mathrm{b}}$ Molar conversion indicates the percentage of vanillic acid/vanillin molar yield produced from the molar consumption of ferulic acid during A. niger fermentation

PCL liquor. According to the study by Srivastava et al. [33], A. niger was expected to produce vanillin from eugenol through a metabolic pathway with ferulic acid as an intermediate metabolite (as shown in Fig. 1). This metabolic pathway was constructed based upon the reference pathway in P. fluorescens. During ferulic acid metabolism by $P$. fluorescens, vanillic acid is secreted as the end product following the action of vanillin dehydrogenase enzyme in the bioconversion of vanillin [10]. Therefore, assuming that $A$. niger followed a similar ferulic acid metabolic pathway as $P$. fluorescens, the vanillin dehydrogenase enzyme expression during ferulic acid metabolism was believed to be the factor that caused the accumulation of vanillic acid during the ferulic acid fermentation by $A$. niger. As reported by Lindahl [34], aldehyde compounds rarely accumulate as an end product in the biological system because of its high chemical reactivity. Therefore, various enzyme systems exist simultaneously in the cell metabolism to metabolize aldehyde into less reactive derivatives such as carboxylic acid.

During the PP and PCL liquors fermentation, the interplay of feeding modes, ferulic acid and NFPC content in the feeding liquors may affect the accessibility of ferulic acid and NFPC to $A$. niger. The responses of $A$. niger to its environmental changes may disturb the activation/inhibition mechanism of its enzyme system in the cell. PP and PL liquors which are rich in various phenolic compounds may exert some extra effects on the cell physiology and its metabolic pathway. Therefore, we strongly believed that the combined effects of high ferulic acid and NFPC content during LVF fermentation caused vanillin excretion as 


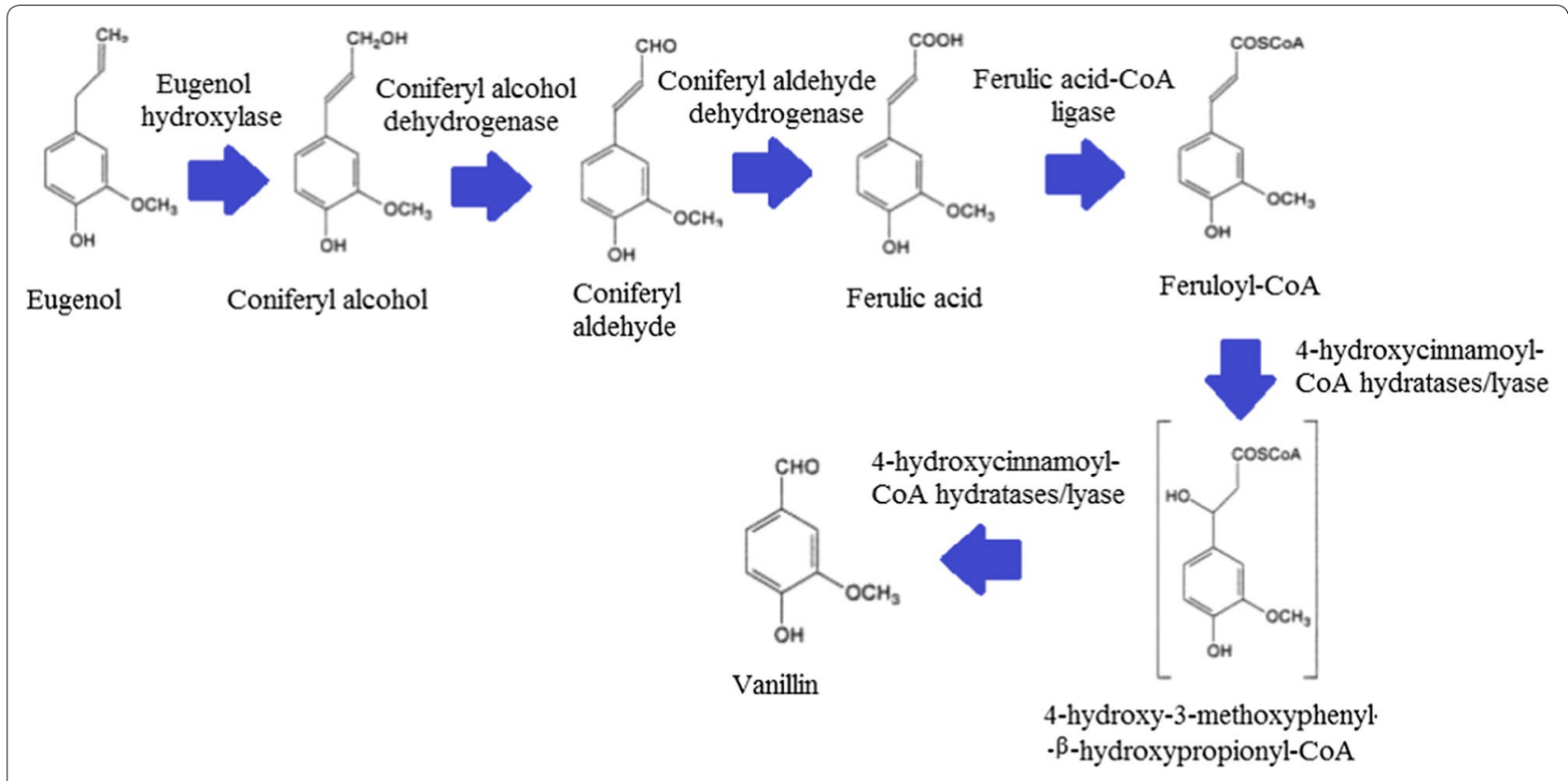

Fig. 1 The proposed metabolic pathway of Aspergillus niger in vanillin production from eugenol by Srivastava et al. [33]

an overflow intermediate metabolite during ferulic acid metabolism. A similar finding was reported in the study by Muheim and Lerch [19], where Streptomyces setonii excreted vanillin as an overflow metabolite when the vanillic acid content reached $200 \mathrm{mg} \mathrm{L}^{-1}$. In our study, LVF of both PP and PCL liquor produced about $6.4 \mathrm{mg} \mathrm{L}^{-1}$ vanillic acid, but the yield of vanillin was different.

Direct formation of vanillin at high yield by means of biotechnological approaches was seldom reported, as vanillin is well-known to inhibit cell metabolism. Thus, most microbes possess a specific enzyme system that tends to oxidize or reduce the vanillin compound into derivatives such as vanillic acid, vanillyl alcohol, guaiacol, protocatechuic acid etc. [19,35]. Although a definite ferulic acid metabolic pathway of $A$. niger still unclear, we strongly believed that the interplay of feeding modes, ferulic acid and NFPC content influenced the metabolic pathway of $A$. niger during its ferulic acid metabolism, leading to the production of vanillin. A high level of ferulic acid and NFPC loading during LVF fermentation probably stimulate the conversion of ferulic acid into vanillic acid, while facilitate the vanillin excretion as an overflow mechanism. This may explain why vanillin was only detected at a significant level in LVF fermentation for both PP and PCL liquors. According to Nicholas et al. [10], vanillin (or vanillic acid) can be produced through various biotechnological means by either single or mixed microorganisms. Various biosynthetic pathways and enzyme systems were reported to participate in this biotransformation process involving different microorganism. Therefore, further study on the genes and proteins involved in the metabolic pathway of $A$. niger during the ferulic acid bioconversion is necessary for a better understanding of the fermentation of this fungus.

In addition, the results also suggest that shifting of feeding mode from SVF to LVF did not improve the vanillic acid molar conversion, but stimulated the accumulation of vanillin in PP liquor fermentation. Nevertheless, the yield and molar conversion of both vanillic acid and vanillin had improved significantly following the shift of the feeding mode from SVF to LVF. This observation further verified the influence of ferulic acid and NFPC concentration on the fermentation efficiency. According to Diana et al. [7], the efficiency of vanillin bioconversion from ferulic acid in crude wheat bran hydrolysate was lower, compared to the ferulic acid liquor that was recovered from the crude hydrolysate. Other compounds such as aldehyde or phenolic compounds that are present in the crude hydrolysate were reported to influence the performance of the microorganisms in fermentation, thereby reducing the molar yield and production of the end products. However, our results reveal that direct feeding of the biomass liquor has its pros and cons. Although the vanillic acid yield and molar conversion were reduced when feeding crude extract, vanillin yield was simultaneously enhanced. Thus, further studies profiling of the phenolic compounds in the pineapple residue liquor should be conducted, so that the influence of a defined compound on the $A$. niger metabolic pathway can be identified. 


\section{Conclusion}

This study proposes a novel use of the phenolic extracts of pineapple peel and crown leaves for the production of vanillic acid and vanillin. Compared to PCL liquor, PP liquor that containing the highest level of ferulic acid and phenolic compounds was shown to be the best substrate for vanillic acid and vanillin production. The interplay of feeding mode, ferulic acid and NFPC content was suggested to be an important factor affecting the efficiency of ferulic acid bioconversion into vanillic acid and vanillin. Furthermore, this study also shows that large volume feeding with liquor with a high ferulic acid content was more effective in enhancing vanillin production.

\section{Supplementary information}

Supplementary information accompanies this paper at https://doi. org/10.1186/s13065-020-0663-y.

Additional file 1. Data of total composition of pineapple peel and pineapple crown leaves has been provided.

Additional file 2. Regression models for the CCDRSM optimization of ferulic acid and NFPC from pineapple peel (PP) and pineapple crown leaves $(\mathrm{PCL})$

\section{Abbreviations}

PP: Pineapple peel; PCL: Pineapple crown leaves; NFPC: Non-ferulate phenolic compounds; NREL: National Renewable Energy Laboratory; CNCM: Collection Nationale de Culture de Microorganisms; $\mathrm{NaOH}$ : Sodium hydroxide; HPLC: High performance liquid chromatography; GAE: Gallic acid equivalent; LVF: Large volume feeding; SVF: Small volume feeding; ANOVA: Analysis of variance; RSM: Response surface methodology; CCD: Central composite design.

\section{Acknowledgements}

The authors acknowledge the School of Chemical Sciences and Food Technology, Faculty of Science and Technology, Universiti Kebangsaan Malaysia for the facilities provided to conduct this research work.

\section{Authors' contributions}

PLT conducted the experiments, data analysis and manuscript writing. $\mathrm{OH}$ conceived the experimental design of this research work. Both authors contributed to the final manuscript. Both authors read and approved the final manuscript.

\section{Funding}

The authors appreciate the Universiti Kebangsaan Malaysia for the financial support under the grant scheme with project code no. DIP-2012-018.

\section{Availability of data and materials}

The datasets used and/or analysed in the current study are available from the corresponding author on reasonable request.

\section{Competing interests}

The authors declare that they have no competing interests.

\section{Author details}

1 Department of Bioscience, Faculty of Applied Sciences, Tunku Abdul Rahman University College, Jalan Genting Kelang, Setapak, 53300 Kuala Lumpur, Malaysia. ${ }^{2}$ School of Chemical Sciences and Food Technology, Faculty of Science and Technology, Universiti Kebangsaan Malaysia, UKM, 43600 Bangi, Selangor, Malaysia.

Received: 14 June 2019 Accepted: 18 January 2020

Published online: 03 February 2020

\section{References}

1. Malaysian Pineapple Industry Board. (2015) Annual report 2015. Malaysian Pineapple Industry Board, Malaysia. http://www.mpib.gov.my/en/ publication/?lang=en. Accessed 11 Mar 2019

2. Nadya H, Zainal S, Nadzirah KZ, Siti-Roha AM, Atikah O, Tengku-Elida TZM (2012) Physicochemical properties analysis of three indexes pineapple (Ananas Comosus) peel extract variety N36. APCBEE Procedia 4:115-121

3. Yusof Y, Yahya SA, Adam A (2015) Novel technology of sustainable pineapple leaf fibers productions. Procedia CIRP 26:756-760

4. Banerjee S, Ranganathan V, Patti A, Arora A (2018) Valorisation of pineapple wastes for food and therapeutic applications. Trends Food Sci Technol 82:60-70

5. Chattopadhyay P, Banerjee G, Sen SK (2018) Cleaner production of vanillin through biotransformation of ferulic acid esters from agro residue by Streptomyces sannanensis. J Clean Prod 182:272-279

6. Paz A, Outeirino D, Oliveira RPDS, Dominguez JM (2018) Fed-batch production of vanillin by Bacillus aryabhattai BA03. New Biotechnol 40:186-191

7. Diana DG, Luigi S, Maurizio R, Leonardo S, Fabio F (2009) Production of vanillin from wheat bran hydrolyzates via microbial bioconversion. J Chem Technol Biotechnol 84:1441-1448

8. Torres BR, Aliakbarian B, Torre P, Perego P, Dominguez JM, Zilli M, Converti A (2009) Vanillin bioproduction from alkaline hydrolysate of corn cob by Escherichia coli JM109/pBB1. Enzyme Microb Technol 44:154-158

9. Zheng L, Zheng P, Sun Z, Bai Y, Wang J, Guo X (2007) Production of vanillin from waste residue of rice bran oil by Aspergillus niger and Pycnoporus cinnabarinus. Bioresour Technol 98:1115-1119

10. Walton NJ, Narbad A, Faulds CB, Williamson G (2000) Novel approaches to the biosynthesis of vanillin. Curr Opin Biotechnol 11:490-496

11. Kaur B, Chakraborty D (2013) Biotechnological and molecular approaches for vanillin production. Appl Biochem Biotechol 169:1353-1372

12. Buranov AU, Mazza G (2008) Lignin in straw of herbaceous crops. Ind Crop Prod 28:237-259

13. Mathew S, Abraham TE (2006) Bioconversion of ferulic acid, a hydroxycinnamic acid. Crit Rev Micrcobiol 32:115-125

14. Gopalan N, Nampoothiri KM (2018) Biorefining of wheat bran for the purification of ferulic acid. Biocatal Agric Biotechnol 15:304-310

15. Gadalkar SM, Rathod VK (2017) Pre-treatment of ferulic acid esterases immobilized on MNPs to enhance the extraction of ferulic acid from defatted rice bran in presence of ultrasound. Biocatal Agric Biotechnol 10:342-351

16. Xi J, Luo S (2016) The mechanism for enhancing extraction ferulic acid from Radix Angelica sinensis by high hydrostatic pressure. Sep Purif Technol 165:208-213

17. Bonnin E, Saulnier L, Brunel M, Marot C, Lesage-Meesen L, Marcel A, Thibault JF (2002) Release of ferulic acid from agroindustrial by-products by the cell wall degrading enzymes produced by Aspergillus niger 1-1472. Enzyme Microb Technol 31:1000-1005

18. Ong KL, Tan BW, Liew SL (2014) Pineapple cannery waste as a potential substrate for microbial biotransformation to produce vanillic acid and vanillin. Int Food Res J 21:953-958

19. Muheim A, Lerch K (1999) Towards a high yield bioconversion of ferulic acid to vanillin. Appl Microbiol Biotechnol 51:456-461

20. Lesage-Meessen L, Delattre M, Haon M, Thibault JF, Ceccaldi BC, Brunerie P, Asther M (1996) A two-step bioconversion process for vanillin production from ferulic acid combining Aspergillus niger and Pcynoporus cinnabarinus. J Biotechnol 50:107-113

21. Hames B, Ruiz R, Scarlata C, Sluiter A, Sluiter J, Templeton D (2008) Preparation of samples for compositional analysis: Laboratory Analytical Procedures (LAP). Technical Report NREL/TP-510-42620. Golden: National Renewable Energy Laboratory (NREL)

22. Sluiter A, Hames B, Ruiz R, Scarlata C, Sluiter J, Templeton D, Crocker D (2008) Determine of structure carbohydrates and lignin in biomass: Laboratory Analytical Procedures (LAP). Technical Report NREL/TP-510-42618. Golden: National Renewable Energy Laboratory (NREL)

23. Sluiter A, Hames B, Ruiz R, Scarlata C, Sluiter J, Templeton D (2005) Determine of ash in biomass: Laboratory Analytical Procedures (LAP). Technical Report NREL/TP-510-42622. Golden: National Renewable Energy Laboratory (NREL)

24. Sluiter A, Ruiz R, Scarlata C, Sluiter J, Templeton D (2005b) Determination of extractives in biomass: Laboratory Analytical Procedure. Technical 
Report NREL/TP-510-42619. Golden: National Renewable Energy Laboratory (NREL)

25. Praveen KR, Awang B (2007) Antioxidant activity, total phenolic and flavonoid content of Morinda citrifolia fruit extracts from various extraction processes. J Eng Sci Technol 2:70-80

26. Pilanee V, Waraporn A (2009) Feasibility study on vanillin production from Jatropha curcas stem using steam explosion as a pretreatment. Int J Agr Biosyst Eng 3:258-261

27. Christelle S, Laurence LM, Julie O, Olivier B, Georges B, Benoit CC, Marcel A (2000) Design of a fungal bioprocess for vanillin production from vanillic acid at scalable level by Pycnoporus cinnabarinus. J Biosci Bioeng 89:223-230

28. Smith BG, Harris PJ (2001) Ferulic acid is esterified to glucuronoarabionoxylans in pineapple cell walls. Phytochem 56:513-519

29. Torre P, Aliakbarian B, Rivas B, Dominguez JM, Converti A (2008) Release of ferulic acid from corn cobs by alkaline hydrolysis. Biochem Eng J 40:500-506

30. Mussatto SI, Dragone G, Roberto IC (2007) Ferulic and p-coumaric acid extraction by alkaline hydrolysis of brewer's pent grain. Ind Crop Prod 25:231-237
31. Lam TBT, Kadoya K, liyama K (2001) Bonding of hydroxycinnamic acids to lignin: ferulic and $p$-coumaric acids are predominantly linked at the benzyl position of lignin, not the $\beta$-position, in grass cell walls. Phytochem 57:987-992

32. Noor-Hasyierah MS, Mohamed-Zulkali MD, Dachyar A, MuhammadSyarhabil A, Ku-Syahidah KI (2011) Optimization of alkaline hydrolysis of paddy straw for ferulic acid extraction. Ind Crop Prod 34:1635-1640

33. Srivastava S, Luqman S, Khan F, Chanotiya CS, Darokar MP (2010) Metabolic pathway reconstruction of eugenol to vanillin bioconversion in Aspergillus niger. Bioinformation 4:320-325

34. Lindahl R (1992) Aldehyde dehydrogenase and their role in carcinogenesis. Crit Rev Biochem Mol Biol 27:283-335

35. Ghosh S, Sachan A, Sen SK, Mitra A (2007) Microbial transformation of ferulic acid to vanillic acid by Streptomyces sannanensis MTCC 6637. J Ind Microbiol Biotechnol 34:131-138

\section{Publisher's Note}

Springer Nature remains neutral with regard to jurisdictional claims in published maps and institutional affiliations.
Ready to submit your research? Choose BMC and benefit from:

- fast, convenient online submission

- thorough peer review by experienced researchers in your field

- rapid publication on acceptance

- support for research data, including large and complex data types

- gold Open Access which fosters wider collaboration and increased citations

- maximum visibility for your research: over $100 \mathrm{M}$ website views per year

At BMC, research is always in progress.

Learn more biomedcentral.com/submissions 